\title{
Article
}

\section{David Strohmaier}

\section{Group Membership and Parthood}

\author{
Runner-up of the 2018 Essay Competition of the International \\ Social Ontology Society
}

https://doi.org/10.1515/jso-2018-0016

\begin{abstract}
Despite having faced severe criticism in the past, mereological approaches to group ontology, which argue that groups are wholes and that groups members are parts, have recently managed a comeback. Authors such as Katherine Ritchie and Paul Sheehy have applied neo-Aristotelian mereology to groups, and Katherine Hawley has defended mereological approaches against the standard objections in the literature. The present paper develops the mereological approaches to group ontology further and proposes an analysis of group membership as parthood plus further restrictions. While all mereological accounts agree that group members are parts of the group, it has become clear that this analysis is insufficient. I discuss three proposals to develop the mereological analysis of group membership and then put forward a combined solution to the puzzle. According to my proposal, the members of a reading group are agents who are part of the group and have been designated to contribute to the group.
\end{abstract}

Keywords: Group ontology; Mereology; Group membership; Katherine Ritchie; Katherine Hawley.

\section{Introduction}

Although mereological approaches to group ontology, which argue that groups are wholes and that group members are their parts, have faced severe criticism in the past (e.g. Ruben 1985; Uzquiano 2004; Effingham 2010), they have

David Strohmaier, University of Cambridge, Department of Computer Science and Technology, Cambridge, United Kingdom of Great Britain and Northern Ireland, e-mail: davidstrohmaier92@gmail.com. https://orcid.org/0000-0002-1430-8212 
recently managed a comeback. This resurgence of mereological analyses of groups is exciting insofar it promises to include a key topic of social ontology in well-established metaphysical programs such as those offered by Fine (1999) and Koslicki (2008).

Mereological approaches to groups have managed their comeback by breaking with the tenets of classical extensional mereology. As we will see, the extensionality requirement that wholes are individuated by their (material) parts creates trouble for an analysis of groups. In response, some proponents, such as Ritchie (2013, 2015) and Sheehy (2006a,b), have edged towards a neo-Aristotelian mereology, which grants structure a greater role relative to material parts. Many issues raised in the literature disappear with this move.

In the most recent defence of the mereological approach, Hawley (2017) leaves open which specific mereological system she endorses. According to her proposal, it suffices that mereological theories clearly have the capacities to address all objections one way or another. We can argue that a mereological approach to groups works before settling on the specific axioms.

But even so a challenge persists for mereological approaches: How are we to analyse group membership? While all mereological accounts agree that group members are parts of their group, we shall see that this characterisation remains insufficient. The present paper develops the mereological approach to group ontology further and proposes an analysis of group membership as parthood plus further restrictions. According to my proposal, the members of a reading group are agents who are part of the group and have been designated to contribute to the group's functioning.

The argument proceeds as follows: At the outset, I discuss the notion of social groups and the importance of the membership relation for them. Then, drawing on Hawley's work, I introduce three challenges to the mereological analysis of groups. The first two challenges make us aware of the problems associated with the extensionality requirement, but the most important one is the third challenge which raises the issue of the transitivity of parthood. While parthood is transitive, group membership does not seem to be. The general solution is straightforward: impose further restrictions, that is analyse group membership as parthood plus some further requirements.

The remainder of the paper discusses how to specify group membership beyond parthood. The current literature offers three proposals: one by Hawley, one by Nick Effingham (although he rejects it in the end), and one by Achille Varzi. I argue that these proposals are insufficient on their own, but that put together they solve the problem of how to analyse group membership within the mereological framework. As noted above, I conclude that a part of a group 
is a member if and only if it is an agent which is designated to contribute to the group's functioning.

\section{On Groups}

Before I turn to the analysis of group membership, I need to indicate the scope of the inquiry and what unites its objects. As is common in the debate (e.g. Thomasson 2016; Epstein 2017), I use "social group" in a broad sense and interchangeably with "group". The exact boundaries of the term are disputed. Some want to include organisations and nations, such as Microsoft and the UK; others doubt that one analysis can cover all these cases. Recent literature (e.g. Hawley 2017) tends to focus on smaller groups and, hence, discusses the departmental reading group rather than Microsoft.

Another complicating case are collections of humans, which appear to be united only by sharing one or multiple features, for example races and gender groups. Some authors, such as Ritchie (2013, 2015), argue that while these cases should count as groups, they are not susceptible to the same analysis as the departmental reading group or Microsoft. Gender groups and the like would lack the functional structure readings groups have. The following analysis of group membership as mereological parthood plus further restriction cannot be applied to such groups if they are not susceptible to a mereological analysis. However, towards the end of the paper I will address a worry that my analysis faces particular problems regarding these cases.

Beyond the general limitations of mereological accounts of groups, the present paper is based on only one generalisation about social groups: all social groups can have group members. The reading group has members and if Microsoft is a group, then it has group members too. Accordingly, the membership relation characterises social groups. All groups have members at some time in some possible world. ${ }^{1}$

Group membership serves as a starting point for analysing groups and therefore the question of how groups relate to their members arises. It is the uniting feature of the present subject matter. Those who want to reduce groups, for

1 Epstein (2015, p. 158-161) has suggested that some groups have no members at least for some time. Perhaps the Supreme Court existed before its first member was appointed or perhaps it would continue to exist even if all members were to resign at once. This suggestion is compatible with my assertion that all groups can have members. 
example to mereological wholes, must reduce the membership relation. Typically, providing necessary and jointly sufficient conditions serves as such a reduction. But offering such conditions proves trickier than one might expect at first. ${ }^{2}$

According to a naïve mereological approach, group membership just reduces to being a part in a social group, that is one is a member if and only if one is part of the group. Considering more closely how members relate to their groups, however, reveals serious challenges for this first approximate analysis, which have received attention in the literature.

\section{Challenges for the Mereological Analysis}

Katherine Hawley has helpfully summarised the standard objections to the mereological analysis of groups. I offer a quick reminder of three types ${ }^{3}$ of objections she discusses, to then focus on a version of the last, which pertains to the transitivity of parthood and raises doubts for whether group membership can be analysed as parthood.

\subsection{Objections from Temporal and Modal Flexibility}

Groups undergo change in regard to their members over time and across possible worlds (cf. Hawley 2017, p. 5). While I am currently a member of the departmental reading group, my membership will cease when I leave the department. The group will continue to exist. According to classical extensional mereology, however, sums are individuated by their parts so that they cannot undergo change in regard

\footnotetext{
2 If a reduction by offering necessary and jointly sufficient conditions is so challenging, then why spend time trying it? Commonly, such reductions have been taken to increase the parsimony of a metaphysical system and thereby its appeal. Thomasson's contribution to the debate questions this reasoning, throwing further doubt on whether it is a venture worth undertaking. However, Thomasson's argument relies on her generally deflationist approach to metaphysics, which suggests that the parsimony achieved through the reduction is of little value. For all those endorsing another metaontological stance, the appeal persists. Furthermore, the reduction allows for a seamless integration of the ontology of groups into a mereological approach to the metaphysics of ordinary objects. That such an integration is a possible theoretical move is itself a result of interest for which my paper argues.

3 I neglect a fourth type Hawley (2017, p. 13-15) addresses: the objection from location. This worry is more specific than the other three and leads us beyond the question of how to analyse the group membership relation.
} 
to them and persist. It seems then that the group members cannot be mereological parts of their groups.

But as Hawley notes, not all systems of mereology endorse this extensionality requirement. Both Sheehy $(2006 a, b)$ and Ritchie $(2013,2015)$ analyse groups as neo-Aristotelian wholes and both deny that mereological wholes are individuated by their material parts, as material sums are within classical extensional mereology. ${ }^{4}$ As Sheehy puts it, "[g]roups are composite material particulars constituted by individuals standing in relations through time" (Sheehy 2006a, p. 140 , see also 2006 b, p. 101), where the relations give the group a functional structure.

Such non-extensional mereological approaches can easily account for the temporal and modal flexibility of groups. The reading group is individuated by features other than the extension of its parts, paradigmatically its functional structure. The neo-Aristotelian accounts also limit what counts as part of the group: the parts must play a functional role within the group. This further requirement for parthood will be considered later, when we attempt to analyse group membership.

\subsection{Objection from Coextensional Groups}

As mentioned, within classical extensional mereology, mereological sums are individuated by their proper parts. Accordingly, distinct sums cannot share all their proper parts. Groups, in contrast, can share all their members while remaining distinct. Even if at all times every member of the reading group is a member of the chess club and vice versa, the two groups are not identical. The reading group has different properties than the chess club. For example, the reading group might be allowed to book rooms in the department while the chess club enjoys no such privileges. By Leibniz's Law, no objects which differ in their properties can be identical and therefore the two groups are distinct. Again, it appears that making the members parts creates a problem for group ontology.

Hawley (2017, p. 9-13) notes a number of straightforward responses to this problem, one of them being a rejection of extensional mereology. For example,

\footnotetext{
4 As noted, Ritchie does not include groups without organisational or functional structure in this analysis. In addition, Ritchie never calls the members "parts". Instead Ritchie (2015, p. 316) writes that whatever occupies a node in the structure of a group is a member. But she likens her approach to the neo-Aristotelian mereology of Fine (1999) and Koslicki (2008) and presents her account as "a view of groups as structured wholes" (2015, p. 316). In light of these quotes, interpreting the node-occupying individuals as neo-Aristotelian parts appears warranted.
} 
Sheehy and Ritchie's neo-Aristotelian mereology of groups solves the problem by individuating social groups not just by their members but also their structure. Groups like the department reading group and chess club can have all the same material parts and therefore spatially coincide, while "they remain distinct entities in virtue of the different ways in which the parts are organised and related" (Sheehy 2006a, p. 140). The functional relations or organisation differentiate the groups despite their overlap in material parts. Again, such a non-extensional mereology narrows down what counts as a part by requiring functional contribution to the group.

\subsection{Objection from the Transitivity of Parthood}

The transitivity of parthood creates a further problem for analysing group members as parts. The parts of group members are not themselves members. Even though my hand is part of me and I am a member of the reading group, my hand is not a member of the reading group. If membership reduced to mereological parthood, my hand would become a member of the reading group. Since my hand is not a member of any reading group, we cannot reduce membership to parthood, or so the objection goes.

In contrast to the first two, this third objection does not disappear with the endorsement of neo-Aristotelian mereology. Giving functional structure a mereological role does not imply the denial of transitivity. Kathrin Koslicki, on whose neo-Aristotelian mereology Katherine Ritchie's group ontology explicitly draws, endorses the transitivity of parthood (see Koslicki 2008, p. 12, 78). Being forced to deny the widespread transitivity assumption would be a considerable cost for any system of mereology..$^{5}$ Our ontology of groups should not commit us to denying this assumption. The mereological analysis of groups should find another way to avoid the result that all parts of the members of a group count as members.

The most promising solution is to narrow down the notion of membership. Not all parts of groups are members, but only those parts fulfilling further requirements. My hand and I are both mereological parts of the departmental reading group, but we are not both members because to be a member in the reading group is to be a part of it and meet some additional condition. Hawley (2017, p. 8) compares this analysis to the notion of an organ of a dog: while a dog's organ is a

5 Although it is widely accepted, Kit Fine rejects it (see Koslicki 2008 reporting on correspondence with Fine). 
part of the dog, not every part of the dog is an organ. There are further requirements on being an organ beyond being a part and the same goes for membership. But which additional restrictions should we impose on group membership? This question drives the remaining sections of the paper.

\section{Restricting Parthood to Membership}

There are at least three proposed requirements for group membership as parthood in the debate. I will present all of them and argue that none is sufficient on its own, but that in combination they do the trick.

\subsection{The First Proposal}

The first proposed requirement can be found in Hawley's paper. In fact, there are two ways to read this aspect of her paper. To make the present interpretation clear, consider the following paragraph:

\footnotetext{
"What then does determine which of the parts of a group are its members? It varies, but here is an example. The Institute of Philosophy (IP) in London offers membership both to individual philosophers and to philosophy departments of universities in the United Kingdom. Professor Gromit is a member of the Department of Philosophy at the University of Wensleydale, and the Wensleydale department is a member of the IP. Is Professor Gromit a member of the IP, in virtue of his being a member of a member of the IP? We do not try to answer this question by considering the metaphysics of social groups. Instead, we consult the website of the IP, where we find that members of institutional members are not automatically members of the IP; evidently, the IP could have adopted different regulations, rendering membership transitive." (Hawley 2017, p. 8)
}

One way to interpret this passage is to attribute a kind of quietism to Hawley: while she is aware of the need for a restriction, she would not want to settle on anything specific and rather delegate the task to another field. The sentence "We do not try to answer this question by considering the metaphysics of social groups" suggests this reading, but it is the less charitable one.

On this uncharitable interpretation, Hawley would neglect group membership as a unifying characteristic of social groups. All groups have group members at some time in some possible world. Accordingly, every complete metaphysics of groups must offer an analysis of group membership. Consider Hawley's own analogy between members and organs. An account of organisms would be seriously deficient if it did not include an analysis of what it is to be an organ. 
Likewise, an account of social groups which leaves the criteria for group membership open would be incomplete at best.

The other reading of Hawley's position is more promising: She suggests that the groups or their environment impose the specific restriction. A member would be a part of the group which meets the membership restrictions imposed in this social context. In the case of the Institute of Philosophy, these restrictions are laid down as formal rules. On other occasions they might be informal and even externally imposed on the group. Metaphysics says something about the further restriction on parthood, namely that the designation as a member makes the difference. This reading suggests the following analysis of group membership:

A part of a group is a member of this group if and only if,

1. it is designated in the appropriate way as such.

This proposal solves the transitivity problem as presented by Hawley. While both my hand and I are parts of the reading group, only I am a part which has been appropriately designated as a member.

One major difficulty this approach faces is to specify what designation involves. Hawley's example is very suggestive. The Institute of Philosophy has presumably clear and explicit rules for who counts as a member. Other cases put more pressure on the proposal. Brian Epstein's The Ant Trap (2015) and his paper on group ontology (2017) suggest open-mindedness about who or what could make it the case that certain agents are members of a group. Consider for example, Epstein's extensive discussion of the US Supreme Court, which clearly cannot designate its own members (Epstein 2015, p. 150-168). The rules for designation are far from trivial, even though they are laid down in a formal manner.

The issue of how to analyse "designation as a member" also depends on how far one takes groups to extend. If one wants to include gender groups as social groups in this analysis, then "designation" must pick out a far broader phenomenon. ${ }^{6}$ If one wants to call a colony of ants a group, then we must broaden the scope even further and perhaps start to take scents as designating features. To avoid having to rule on how encompassing our analysis of groups should be, I will simply grant that proponents of narrowing group membership down in this way can find a solution to the problem. ${ }^{7}$

6 Ritchie $(2013,2015)$ instead suggests that we need to analyse such feature groups in a non-mereological way.

7 I will, however, later raise the issue of what the parts are designated as. That members are parts which are designated as members threatens to create a problematic circularity. I bracket this issue at this point for the sake of the paper's dialectic. 
Even so, the proposal suffers from a major drawback, which I take to be conclusive: Only a limited range of objects can be members of social groups. My hand, for instance, cannot be a member of any social group, regardless of the group's rules. In contrast to set membership and parthood, group membership takes only certain objects as relata. No matter what the Institute of Philosophy statutes say, my hand is just not the kind of thing that can be a group member.

Or, to mention another example, consider the Supreme Court again. Even if in a fit of madness Congress, the White House, and the other required political bodies were to change laws and constitution so as to designate stones as the members of the Supreme Court, it would be wrong to say that the stones are the members of the social group. While it might be controversial whether the Supreme Court would even be a social group at this point, I rely on the assumption that it certainly is not a social group with stones as its members, regardless of formal or informal designations. The attempt to solve the transitivity problem purely by adding designation as a further requirement fails to account for why stones or hands cannot be group members. An account which solves the transitivity problem and explains why group membership is limited to certain objects would be preferable.

\subsection{The Second Proposal}

The second proposal addressing the transitivity problem evades the issue of stones and hands. Effingham (2010, p. 255), who endorses an analysis of groups as complex sets, discusses the transitivity objection against analysing groups as sums and points to a solution: only those parts of the group which are persons are members. ${ }^{8}$ Accordingly, my hand cannot be a member of the reading group although I am a member of it. While Effingham ends up rejecting this solution, it promises to solve the transitivity problem for mereological accounts.

There is, however, also a problem with this proposal and it becomes clear by considering examples of nested groups, that is group within groups. Hawley offers one example of this kind:

“Suppose that (1) all and only haberdashers are members of the Haberdashers' Union; (2) all and only local chapters of the HU are members of the Congress of Haberdashers' Union Chapters; (3) all and only the members of the HU are members of chapters that are members of the CHUC. Then the HU and the CHUC are the same material object, having

8 I will in the following talk of agents rather than persons. The reason being that "agent" has a slightly larger extension than "person" on some interpretations. The family dog might be an agent without being a person. To allow the family dog to be a family member, I use the slightly broader term. Otherwise, nothing hangs on this terminological difference. 
the same parts, but they have different members (the HU has only individual members, the CHUC has only chapter members).” (Hawley 2017, p. 12-13)

Limiting group membership to agents does not help in this case. All members of one group would have to be members of other groups. While my hand would not be a member of the reading group, group membership would have to be transitive. The examples of nested groups show that it is not. Although the members of the Haberdashers' Union fulfil the agency requirement, they are not members of the Congress of Haberdashers' Union Chapters. The new requirement suggested (but not endorsed) by Effingham does not suffice on its own, but a solution is readily at hand.

To solve the troubles with the CHUC, we combine the first two proposals. As Hawley suggested, group members must be designated by the group; and as following Effingham's suggestion, they must be agents. We now have a promising mereology-based analysis of group membership:

A part of a group is a member of this group if and only if,

1. it is an agent,

2. and it is designated as a member in the appropriate way.

On this proposal the members of member of the CHUC are not members of the CHUC unless designated as such. In addition, the proposal rules out that hands could ever be members of a social group, regardless of the designation.

A problem still lingers in the background, however. To analyse group members as those which are designated raises the question what they are designated as. As it stands, an uncomfortable circularity threatens. The designation seems to be just the designation of being a member. In the case of the Institute of Philosophy the statutes might in fact describe the designation of the relevant parts by using the term "member". But the analysis of group membership should not refer to group members at the pain of introducing a circularity undermining the reductive approach. As it stands, membership seems to bootstrap itself.

While such problems of circularity arise frequently in social ontology (e.g. Searle 1995), the issue motivates considering other options to avoid the transitivity problem without running into a potentially vicious circle. I will in the end propose that the agents are designated as something but not directly as members. The best way to get to this conclusion is to consider the third proposal for restricting parthood to membership.

\subsection{The Third Proposal}

The third proposal can be found in a general discussion of the transitivity of parthood by Varzi (2006). Consider his following example: 
"An arm may be part of a musician who is part of an orchestra, yet no arm is part of an orchestra.”

While the transitivity of parthood appears to be violated in this example, Varzi argues that this impression results from a limited use of "part" in ordinary language. We use "part" to refer to functional parts, which are mereological parts that fulfil a certain function for an object. Like Hawley, Varzi argues that the apparent violation of transitivity results from a further restriction on parthood. The arm is literally a mereological part of the orchestra, and any contrary intuitions result from an implicit limitation on "part" within ordinary language. Varzi suggests that the arm does not play the right functional role in the orchestra to be a member. Following Varzi's lead, we might propose that membership resembles functional parthood; thereby limiting membership not only to parts who are individuals, but to parts which play a certain functional role in the group.

On its own this solution lacks appeal. Finding an appropriate functional relation for limiting membership poses a difficult challenge. The functional roles of members might differ from group to group. Certainly, the members of a reading group fulfil other functional roles than the members in a group of friends, or the members of the Supreme Court. As a result, the specification of these functional roles would have to be extremely thin. One might propose that parts only have to fulfil some functional role, no matter which, to be members. But that would make being a member too easy. My hand fulfils some functional role in the reading group, for example, when I hold the door open for others to enter the room. Such troubles increase even further upon endorsing the non-extensional neo-Aristotelian mereology suggested by Ritchie and Sheehy: to be a part already entails playing a function in the organised whole according to their proposal. All parts of the group would again have to be members.

Hence, the Varzi-type functionality proposal leads to a dilemma. On the one hand, we do not want to specify the functional relation in any detail to keep the analysis of group membership general enough to include all examples. On the other hand, if we keep the relation generic, we fail to restrict group membership sufficiently. While endorsing this third proposal avoids the previous circularity issues, we just end up between a rock and hard place.

\subsection{The Combined Solution}

Three different proposals are on the table and none of them succeeds on its own. The first two appeared promising in combination, but the designation threatened to introduce some worrying circularity. If we combine all three proposals, 
however, we find a successful mereology-based analysis of group membership. We can take Varzi's idea that contribution to the group's functioning plays a role and use it to answer the question as what parts need to be designated to become group members. Thus, I propose the following unified solution:

A part of a group is a member of this group if and only if,

1. it is an agent,

2. and it is appropriately designated to contribute to the group's functioning.

I am a member of the reading group because I am a part of it, an agent, and I have been appropriately designated as contributing to its functioning. My hand, although it might be a mereological part of the group and contribute to its functioning, cannot be a member, because it is not an agent. It is also not designated in the way I have been by putting myself on the appropriate email list.

Likewise, the members of the Haberdashers' Union are agents, but they are nonetheless not members of the Congress of Haberdashers' Union Chapters because they are not designated to contribute to the Congress' functioning. In this case, the designation probably has to occur according to the rules outlined in the Congress' statutes. The requirements for an appropriate designation would thus be formal in this example.

The solution also avoids the problematic circularity of the original designation proposal..$^{9}$ The members are not designated as members but as contributing to the group's functioning. Of course, such designation can occur by describing who is a member, as the statutes of the Institute for Philosophy do, but there is no longer a conceptual circularity. Thus, the combined solution covers typical cases such as institutes, departmental groups, and corporations.

One might question whether there is any functioning to contribute for more loosely or unorganised groups, such as gender groups and races. I will address this worry in the next section.

\footnotetext{
9 It does not, however, avoid the challenge of specifying "designation" further. As mentioned above, settling this issue requires committing to how far one wants to extend the analysis of groups. In the core cases, the requirements of appropriate designation are clear enough: They are either laid down in an constitution or depend on the general norms surrounding a kind of group such as reading groups. The less central cases, especially if one seeks to extend social groups beyond those made up of human agents, would demand a further specification. A fully developed account of group ontology would have to resolve this issue, but my proposal seeks to provide an analysis that is suitable for a large variety of mereology accounts and therefore cannot be fully specific. Hence, I leave the issue open.
} 


\section{The Functioning of Unorganised Groups}

As mentioned, groups such as gender groups and races have been recognised in the literature as occupying a special position. Ritchie $(2013,2015)$ prominently distinguishes these unorganised or feature groups from organised groups. These unorganised groups pose a challenge to my proposal insofar it is hard to see what it means to contribute to their functioning. In the case of a departmental reading group to contribute to the functioning is to read the texts and to participate in the discussion, but to what functioning are women designated to contribute?

While the functioning in these cases might be less overt, I argue that my analysis of group membership can cover them nonetheless. It has been suggested by Thomasson (2016) that we use concepts of groups because they give normative structure to our lives. Groups have norms that apply to their members. Thus, for the often used examples of unorganised groups we can understand the members to be designated as contributing to the functioning by keeping the associated norms up and living by them. ${ }^{10}$ Hence, to then apply my proposed analysis to groups such as races and gender groups, one only has to include normative functioning as well as organisational functioning in what the members are designated to contribute to.

However, one might push the counter-example further and argue that one day gender groups could lose their role as normatively structuring our lives. Could it not be that in a far future, there are no gendered norms of living toward which women and men are respectively designated to contribute? I do not rule out such a scenario and my solution would not work for such cases, but I am happy to except this conclusion.

If we were to reach the indicated social situation, then gendered groups would have ceased to exist as social groups. After all, much of the literature (e.g. Ritchie 2013, 2015; Thomasson 2016) agrees ${ }^{11}$ that while we loosely talk of the group of people with brown hair and blues eyes, this is not a social group in the sense the debate is concerned with, but merely a collection of people. In our hypothetical future, what are now races and gender groups would have been replaced by similar collections. ${ }^{12}$ In sum, the analysis is broad enough to

10 This is not the only available option. For example, on the basis of a classical Marxist analysis of classes one could argue that proletarians are designated as contributing to the functioning of their class by selling their labour for production. It seems to me, however, that the key cases currently covered in the literature are best addressed via the sketched norm-focussed approach. 11 Much but not all of the literature: Effingham endorses a much more encompassing account of groups.

12 One might still attempt to offer a mereological analysis for these collections, but the membership conditions would differ. 
encompass our examples of group membership and specific enough to rule out all counter-examples.

\section{Conclusion}

The present paper has provided a mereological analysis of group membership and thereby filled a gap in the existing literature. While Hawley's (2017) recent defence of such a mereological approach has addressed many of the difficulties raised in the group ontology debate, it did not offer an explicit analysis of group membership in terms of parthood, as it neglected to specify in in sufficient detail which requirements characterise group membership. Combining the three proposals by Hawley, Effingham, and Varzi, the present paper solved one of the remaining difficulties for mereological accounts of groups. A part of a group is a member of it if and only if it is an agent which is designated to contribute to the group's functioning.

Funding: Arts and Humanities Research Council, Funder Id: http://dx.doi. org/10.13039/501100000267, Grant Number: AH/L503848/1.

\section{Bibliography}

Effingham, N. (2010): “The Metaphysics of Groups.” In: Philosophical Studies: An International Journal for Philosophy in the Analytic Tradition 149. No. 2, p. 251-267.

Epstein, B. (2015): The Ant Trap: Rebuilding the Foundations of the Social Sciences. New York, NY: Oxford University Press.

Epstein, B. (2017): “What Are Social Groups? Their Metaphysics and How to Classify Them." Synthese. https://doi.org/10.1007/s11229-017-1387-y.

Fine, K. (1999): “Things and Their Parts.” In: Midwest Studies in Philosophy 23. No. 1, p. 61-74. https://doi.org/10.1111/1475-4975.00004.

Hawley, Katherine (2017): "Social Mereology." In: Journal of the American Philosophical Association 3. No. 4, p. 395-411.

Koslicki, K. (2008): The Structure of Objects. Oxford: Oxford University Press.

Ritchie, K. (2013): “What are Groups?” In: Philosophical Studies 166. No. 2, p. 257-272. https://doi.org/10.1007/s11098-012-0030-5.

Ritchie, K. (2015): “The Metaphysics of Social Groups.” In: Philosophy Compass 10. No. 5 , p. 310-321. https://doi.org/10.1111/phc3.12213.

Ruben, D.-H. (1985): The Metaphysics of the Social World. London: Routledge \& Kegan Paul.

Searle, J. R. (1995): The Construction of Social Reality. New York: Free Press.

Sheehy, P. (2006a): "Sharing Space: The Synchronic Identity of Social Groups." In: Philosophy of the Social Sciences 36. No. 2, p. 131-148. https://doi.org/10.1177/0048393106287184. 
Sheehy, P. (2006b): The Reality of Social Groups. Aldershot: Ashgate.

Thomasson, A. L. (2016): Synthese. https://doi.org/10.1007/s11229-016-1185-y.

Uzquiano, G. (2004): “The Supreme Court and the Supreme Court Justices: A Metaphysical Puzzle." In: Noûs 38. No. 1, p. 135-153.

Varzi, A. C. (2006): “A Note on the Transitivity of Parthood." In: Applied Ontology 1. No. 2, p. 141-146. 